\title{
The Role of Anthropomorphic Messengers in Sustainable Participatory Corporate Social Responsibility: Focusing on Messenger's Facial Expression and Participation Effort
}

\author{
Yunjeong Ahn and Jieun Lee* \\ School of Business Administration, Chung-Ang University, 84 Heukseok-ro, Seoul 06974, Korea; \\ anjung02@cau.ac.kr \\ * Correspondence: jlee114@cau.ac.kr; Tel.: +82-2-820-5585
}

Citation: Ahn, Y.; Lee, J. The Role of Anthropomorphic Messengers in Sustainable Participatory Corporate Social Responsibility: Focusing on Messenger's Facial Expression and Participation Effort. Sustainability 2021, 13, 4365. https://doi.org/ $10.3390 /$ su13084365

Academic Editor: Andrea Pérez

Received: 29 March 2021

Accepted: 12 April 2021

Published: 14 April 2021

Publisher's Note: MDPI stays neutral with regard to jurisdictional claims in published maps and institutional affiliations.

\begin{abstract}
This study examines the role of participation effort, focusing on the effect of anthropomorphic messengers' facial expression on consumers' perception in the context of corporate social responsibility (CSR). CSR activities requiring consumer participation can elicit their positive responses. Although companies' interests in participatory CSR are increasing, academic interests in this area are still insufficient. Existing studies have not provided clear results on the effective level of participation effort and its effect on consumers' perception of CSR activities. In this context, we conducted a study that investigated the effect of participation effort, focusing on the facial expression of an anthropomorphic messenger. The study shows that participation effort has a positive relationship with the intention to participate in CSR because consumers perceive messengers with a sad facial expression as victims. However, they perceive messengers with a happy facial expression as marketing agents. Hence, participation effort decreases participation intention. Finally, we discuss the meaning of the study and propose suggestions for future research.
\end{abstract}

Keywords: corporate social responsibility (CSR); consumer participatory CSR; participation effort; anthropomorphic messenger expression; victim; marketing agent

\section{Introduction}

Companies' interests in social activities are increasing with the growing importance of corporate social responsibility (CSR) [1]. This is because CSR not only helps companies to positively contribute toward society, but also strengthens their relationship with stakeholders [2,3]. Therefore, it is an essential factor for the sustainable management of a company [4]. Recently, companies have been increasing consumers' commitment to social issues through participatory CSR that engages consumers in corporate social activities [5]. For example, Coca-Cola conducted social activities in the U.S. using reverse vending machines (RVM), such that it was able to influence consumers to recycle disposable items and donate funds for hosting the Olympics [6]. Similarly, the Seoul Metropolitan Government of Korea conducted a participatory CSR campaign called "art health donation stairs" to support artists with disabilities by collecting donations whenever consumers used the stairs installed in subway stations [7]. However, although companies' interests in participatory CSR are increasing, academic interests in this field are still lacking [5,8]. Participation effort imparted by consumers is one of the most important factors that can affect campaign performance under participatory CSR; however, few studies have examined the level or role of participation effort. Therefore, in this study, we examine the level and role of participation effort required in the context of CSR through the facial expression of anthropomorphic messengers used in participatory CSR.

Anthropomorphism refers to the addition of human characteristics to non-humans [9]. It is a marketing strategy widely used in CSR activities, enabling companies to build relationships with consumers and interact with them [9-11]. Accordingly, companies are 
delivering campaign messages to consumers using messengers that anthropomorphize objects or animals. For example, Ad Council, a nonprofit organization in the U.S., introduced an anthropomorphic bear, referred to as "Smoky Bear", in its wildfire prevention campaign. They anthropomorphized a bear cub that survived a fire in the Lincoln National Forest of south-central New Mexico in 1950 to highlight the meaning of the campaign [12]. Recently, companies have not only been anthropomorphizing messengers, but also conveying their emotions to consumers using messenger's facial expressions. For example, the Journey family of anthropomorphic turtles were presented in Greenpeace's "Save the turtles, protect the oceans" campaign [13] to raise consumers' awareness of environmental protection by conveying the stories of the family who lost their home due to environmental pollution and portraying their sad expressions to consumers. Hence, an anthropomorphic messenger's facial expression has an important influence on how consumers will perceive them. Prior studies suggest that a sad facial expression is more effective in conveying an emotion to consumers than a happy facial expression $[14,15]$. This is because consumers perceive messengers with a sad facial expression as victims, leading them to empathize and sympathize with the messengers; however, they perceive messengers with a happy facial expression as marketing agents, raising doubts about the qualifications of the recipients [16]. Based on this observation, we examine the effect of a messenger's facial expression on consumers' perception and intention to participate in a participatory CSR situation. Moreover, we investigate the effect of participation effort on consumers' perception based on the fact that additional monetary or non-monetary costs incurred by consumers will further activate their positive or negative perception [16]. We seek to provide efficient and strategic suggestions for companies to enjoy successful social activities.

\section{Materials and Methods}

\subsection{Theoretical Framework and Hypotheses}

\subsubsection{Participatory CSR and Participation Effort}

CSR refers to the activities undertaken by companies to achieve social goals beyond their profits [17-19]. Companies not only elicit positive responses from consumers through CSR activities, but also build positive relationships with stakeholders to positively influence corporate evaluation [20-22]. For example, Sen and Bhattacharya [23] showed that CSR activities increase consumers' perceived consistency toward companies and lead to positive corporate evaluation. According to Lee, Kim and Roh [24], consumers who experience altruism through CSR activities think that their psychological distance with their company has become closer, resulting in a positive corporate evaluation. Luo and Bhattacharya [25] suggested that CSR not only positively affects consumer satisfaction, but also enhances the financial performance of companies. Therefore, CSR is a marketing tool that can enhance corporate image and develop positive relationships with consumers. As a result, companies are undertaking CSR in various ways to maximize its positive effects that are beyond the effects of philanthropic CSR. Representative examples include cause-related marketing [26], which links consumers' purchases and donations, and consumer choice-of-cause CSR [27], which determines cause activities based on consumer choices.

Recently, companies have been implementing a new type of CSR to induce consumer participation in CSR activities [5]. Participatory CSR connects consumer participation to social values [8]. According to previous studies, participatory CSR enables an interaction and bond formation between companies and consumers, making consumers more committed to corporate activities $[5,28,29]$. We define participatory CSR in terms of corporate social activities, such that consumer participation, which requires monetary and non-monetary efforts, influences the success of the campaign.

Participatory CSR differs from other types of CSR since it considers consumers' effort. However, although the degree of consumers' effort in CSR has a significant influence on their participation intention and the success of a company's campaign, prior studies do not suggest clear results on the impact of participation effort. Some studies have shown that the participation effort required in campaigns leads to positive corporate evaluation 
because it increases consumers' perception of altruism [8,30]. However, other studies have shown that participation effort increases consumers' perception of cost and causes negative results $[5,8,31]$. Therefore, consumers' participation effort in participatory CSR exhibits both positive and negative effects on their participation intention [8]. However, participation effort alone does not affect consumers' perception or participation intention; it reinforces consumers' perception under CSR. This means that participation effort influences consumers' perception or intention to participate in CSR by interacting with other factors. As the participation effort increases, consumers' positive (negative) perception of CSR becomes more positive (more negative). Previous studies have shown that consumers' effort further activates their perception. For example, Tsai and McGill [32] investigated the impact of consumers' effort related to information processing on their perception. They suggested that consumers who focus on desirability (feasibility) are more likely to perceive desirability (feasibility) when the level of effort is high in comparison to when it is low. Similarly, Ahn and Lee [5] found that consumers can perceive warm glow or costs in CSR, such that their participation effort can further reinforce these perceptions. For consumers who perceive the warm glow aspect in CSR, the participation effort further strengthens consumers' perceived warm glow and positively changes their intention to participate. In contrast, it reinforces perceived costs and negatively changes the participation intention for consumers who perceive costs under CSR. Hence, participation effort strongly activates consumers' perception. Therefore, in order to investigate the influence of participation effort on participatory CSR, it is important to examine consumers' perception of participatory CSR, and the factors that influence it. We examine consumers' perception of participation effort through the facial expression of anthropomorphic messengers.

\subsubsection{Facial Expression of Anthropomorphic Messengers}

The facial expression of messengers acts as the target of benefits in donation or charity-related campaigns; hence, it has been considered as a factor that can stimulate emotions in consumers $[33,34]$. This is because under emotional contagion, the emotions of a messenger are transmitted to consumers, thereby increasing their intention to participate in campaigns [35,36]. Facial expressions used by companies in their campaigns are mainly divided into happiness and sadness [37]. Previous studies have observed that when a messenger's facial expression is sad rather than happy, it has a more positive effect on consumers' participation intention $[14,15]$. Sadness evokes positive emotions, such as empathy and sympathy toward the target, resulting in CSR to be perceived as beneficial. However, happiness reduces the positive emotions that consumers feel toward their target, making them doubt the target's qualifications and invoking negative emotions $[36,38,39]$.

The influence of facial expressions is the same when the target that benefits from CSR is an anthropomorphic object instead of a person. According to previous studies [40-42], emotional relationships and social interactions with consumers may occur when objects are anthropomorphized, that is, the anthropomorphic object's facial expression can cause positive or negative emotions in consumers. For example, Maeng and Aggarwal [43] and Tong, Li, Feng, and Zhang [44] argue that when an object is anthropomorphic, consumers perceive it as a person. Therefore, an anthropomorphic object's facial expression affects consumers in the same way as that of a human. In addition, according to Ketron and Naletelich [16] who investigated the role of anthropomorphic messengers in pro-social behavior, the emotional changes in consumers depend on the facial expressions of messengers, even if they are anthropomorphic. Hence, in the case of anthropomorphic messengers under participatory CSR, sad facial expressions have a more positive effect on consumers' participation intention rather than happy facial expressions.

Furthermore, in this study, we predict that the facial expression of anthropomorphic messengers interact with participation effort, thereby affecting consumers' perception of messengers. According to Ketron and Naletelich [16], consumers may perceive anthropomorphic messengers as victims or marketing agents with commercial persuasion purposes. If consumers perceive an anthropomorphic messenger as a victim, they display a positive 
intention to participate; however, if they perceive it as a marketing agent, they have a negative intention to participate. Accordingly, the messenger's sad expression makes consumers feel empathetic, sympathetic, and compassionate toward it. Hence, due to its sad expression, the messenger is perceived as a victim; therefore, with an increase in participation effort, a greater number of consumers will perceive the messenger as a victim and display an increasingly positive intention to participate. This is because the effort required under CSR further activates consumers' positive or negative perceptions. However, messengers' happy facial expression makes consumers doubt and disagree with its qualifications, such that it is perceived as a marketing agent. Therefore, with an increase in participation effort, a greater number of consumers will perceive the messenger as a marketing agent and display a greater negative intention to participate. This is because participation effort further activates consumers' negative thoughts. In a similar vein, Ketron and Naletelich [16] showed that an additional monetary effort presented to consumers further increases their amount of negative thoughts. Based on the above discussion, we propose the following hypotheses (see Figure 1).

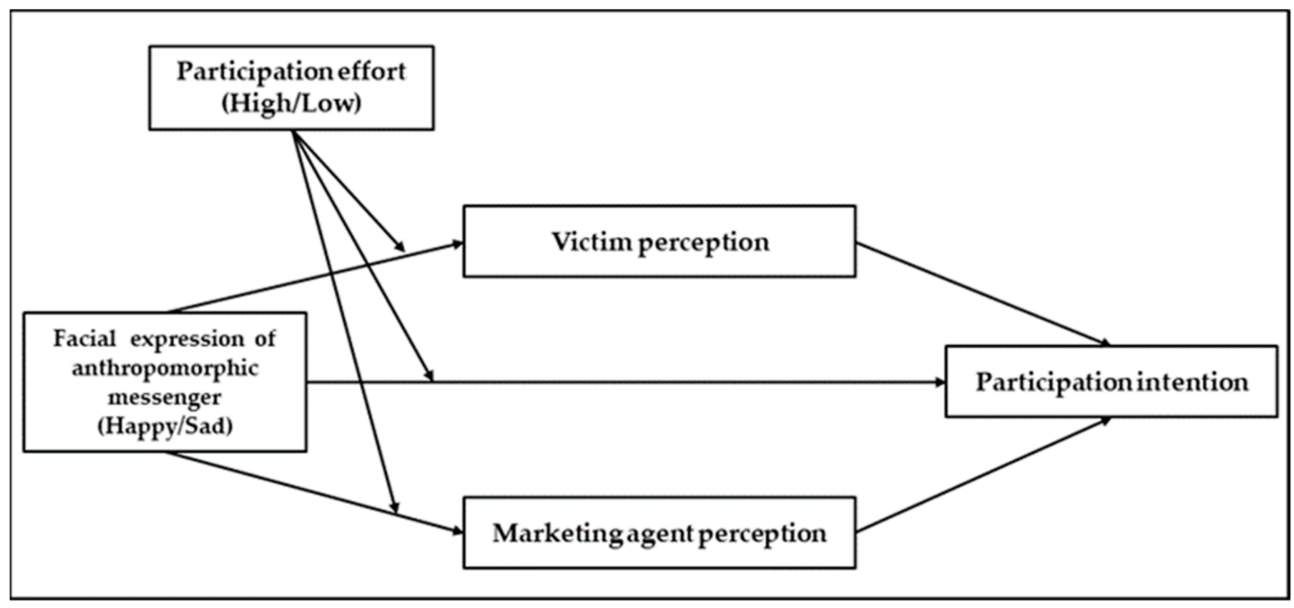

Figure 1. Conceptual model.

Hypothesis 1 (H1). Consumers' perception of an anthropomorphic messenger displaying a sad facial expression as a victim increases when the participation effort is high rather than low. However, the influence of participation effort on victim perception is insignificant when an anthropomorphic messenger displays a happy facial expression.

Hypothesis 2 (H2). Consumers' perception of an anthropomorphic messenger displaying a happy facial expression as a marketing agent increases when the participation effort is high rather than low. However, the influence of participation effort on marketing agent perception is insignificant when an anthropomorphic messenger displays a sad facial expression.

Hypothesis 3 (H3). Under the condition of sad facial expression displayed by an anthropomorphic messenger, consumers exhibit a positive intention to participate in CSR when the participation effort is high rather than low. However, under the condition of a happy facial expression displayed by an anthropomorphic messenger, consumers exhibit a positive intention to participate in CSR when the participation effort is low rather than high.

Hypothesis 4 (H4). The effects of participation effort and facial expression displayed by an anthropomorphic messenger will be mediated by victim perception and marketing agent perception.

\subsection{Methodology}

\subsubsection{Data Collection and Sample}

The study was conducted to examine the differences in consumers' participation intention in the context of CSR with respect to the facial expression of anthropomorphic 
messengers and participation effort. We employed 160 U.S. residents using Amazon Mechanical Turk (MTurk) between 15 November and 18 November 2020 to conduct the survey. They were randomly assigned to one of the four conditions according to the facial expression of anthropomorphic messengers and participation effort. The sample size for each condition consisted of 36 to 44 observations. The participants consisted of 90 males (56.3\%) with an average age of 37.93 (standard deviation $(\mathrm{SD})=11.14$, range $=22-68)($ Table 1$)$.

Table 1. Sample characteristics.

\begin{tabular}{cccc}
\hline & Characteristics & N & \% \\
\hline \multirow{2}{*}{ Gender } & Male & 90 & $56.3 \%$ \\
& Female & 70 & $43.8 \%$ \\
\hline \multirow{3}{*}{ Age } & $20-29$ & 42 & 26.3 \\
& $30-39$ & 54 & 33.7 \\
& $40-49$ & 41 & 25.6 \\
& $50-59$ & 13 & 8.2 \\
& $\geq 60$ & 10 & 6.2 \\
\hline
\end{tabular}

\subsubsection{Development of Experimental Stimuli}

In order to determine the level of participation effort, we conducted a pretest on 26 participants. Participation effort was manipulated according to the number of times consumers participated, following Kivetz and Simonson [45]. Specifically, we set low and high participation effort to use recycling machines for one and 20 times, respectively. We measured participation effort using the three items following Xia, Kukar-Kinney, and Monroe [46]; the participants perceived the participation effort to be higher in the case where recycling was performed 20 times $(M=5.62)$ than the case where it was performed only once $(\mathrm{M}=3.85 ; t=-3.414, p<0.01)$.

\subsubsection{Methods}

We applied a 2 (participation effort: high vs. low) $\times 2$ (facial expression of anthropomorphic messenger: happiness vs. sadness) between-subject factorial design. Participants were exposed to experimental stimuli, including participation effort. The stimuli were produced in four formats according to the anthropomorphic messenger's facial expressions and participation effort (see Appendix A). We produced the facial expression of the anthropomorphic messenger as a happy-faced Earth and a sad-faced Earth based on Ketron and Naletelich [16]. Participation effort was suggested in terms of the number of times recycling was performed, that is once in the case of the low-effort group and 20 times in the case of high-effort group, based on a pretest. The stimuli were created based on a scenario where a company encourages consumers to recycle plastic polyethylene terephthalate (PET) bottles. In this study, the presented company was Adidas, one of the leading manufacturers of sneakers launching eco-friendly products such as "Ultra Boost Uncaged Parley". In this scenario, participants were informed that if they used a vending machine to recycle a certain number of times, Adidas would introduce eco-friendly sneakers made of the plastic. Thereafter, the participants answered questions related to brand attitude, messenger perception (victim and marketing agent), and participation intention. Brand attitude was included in the measurement items as a covariate in order to minimize the influence of external variables that may arise from using the actual brand. Finally, the participants responded to demographic items. The measurement items used in this study and the reliability of the items are presented in Table 2. 
Table 2. Variables and measurement items.

\begin{tabular}{|c|c|c|}
\hline Variables & Items of Measurement & $\begin{array}{c}\text { Cronbach's } \\
\text { Alpha }\end{array}$ \\
\hline Participation effort [46] & $\begin{array}{l}\text { "I need to put a lot of effort in participating in this campaign." } \\
\text { "I have to spend a lot of effort in participating in this campaign." } \\
\text { "I feel that I have spent a lot of effort in trying to participate in this campaign." }\end{array}$ & 0.958 \\
\hline $\begin{array}{c}\text { Brand attitude } \\
\text { [47] }\end{array}$ & $\begin{array}{l}\text { "Adidas is good." } \\
\text { "Adidas is favorable." } \\
\text { "Adidas is positive." } \\
\text { "I like Adidas." }\end{array}$ & 0.945 \\
\hline Victim $[16,48,49]$ & $\begin{array}{l}\text { "I felt sorry for the messenger (the Earth)." } \\
\text { "I wanted to save the messenger." } \\
\text { "I had sympathy for the messenger." } \\
\text { "This messenger is a sincere and potential victim." }\end{array}$ & 0.928 \\
\hline $\begin{array}{l}\text { Marketing agent } \\
{[16]}\end{array}$ & $\begin{array}{l}\text { "I could tell that someone was attempting to influence me through the messenger } \\
\text { (the Earth)." } \\
\text { "I felt that the messenger's request was based on an ulterior motive." } \\
\text { "The messenger's comments are suspicious." } \\
\text { "The messenger is motived to exaggerate the performance of this company." } \\
\text { "This messenger is an agent of the marketer." }\end{array}$ & 0.859 \\
\hline $\begin{array}{c}\text { CSR participation intention } \\
\text { [50] }\end{array}$ & $\begin{array}{l}\text { "I think this campaign is a good idea." } \\
\text { "I would be willing to participate in this campaign." } \\
\text { "It is likely for me to contribute to this cause by getting involved in this campaign." } \\
\text { "I would consider participating in this campaign in order to help the Earth." }\end{array}$ & 0.931 \\
\hline
\end{tabular}

\section{Results}

\subsection{Manipulation Check}

The ANCOVA results of the 2 (participation effort) $\times 2$ (facial expression of anthropomorphic messenger) model for participation effort showed that the main effect of the participation effort was significant $(\mathrm{F}=13.008, p<0.001)$. The participants under high participation effort perceived that more effort was required to participate in CSR ( $M=4.18)$ than those under low participation effort $(M=3.22)$. The influence of other variables was not significant (all, $p>0.1$ ). These results imply the successful manipulation of the participation.

\subsection{Victim Perception}

Following the results of ANCOVA on victim perception, the main effect of the facial expression of the anthropomorphic messenger was found to be significant $(\mathrm{F}=6.274$, $p<0.05)$. Participants perceived the messenger as a victim under the condition of sadness $(\mathrm{M}=5.15)$ more than that under happiness $(\mathrm{M}=4.46)$. In addition, the two-way interaction effect of the facial expression of anthropomorphic messenger and participation effort was found to be significant $(\mathrm{F}=5.794, p<0.05)$. Contrast analysis showed that there is no significant difference in victim perception in the aspect of participation effort under the condition of happiness (high participation effort: 4.31 vs. low: $4.58, \mathrm{~F}=1.877, p>0.1$ ) however, under the condition of sadness, participants perceived the messenger as a victim when the participation effort was high $(\mathrm{M}=5.38)$ than low $(\mathrm{M}=4.88 ; \mathrm{F}=4.186, p<0.05)$ (see Figure 2). Therefore, Hypothesis 1 is supported. Finally, the main effect of brand attitude, a covariate, was found to be significant $(F=28.498, p<0.001)$, showing that the more positive the brand attitude is, the more likely it is for messengers to be perceived as victims. 


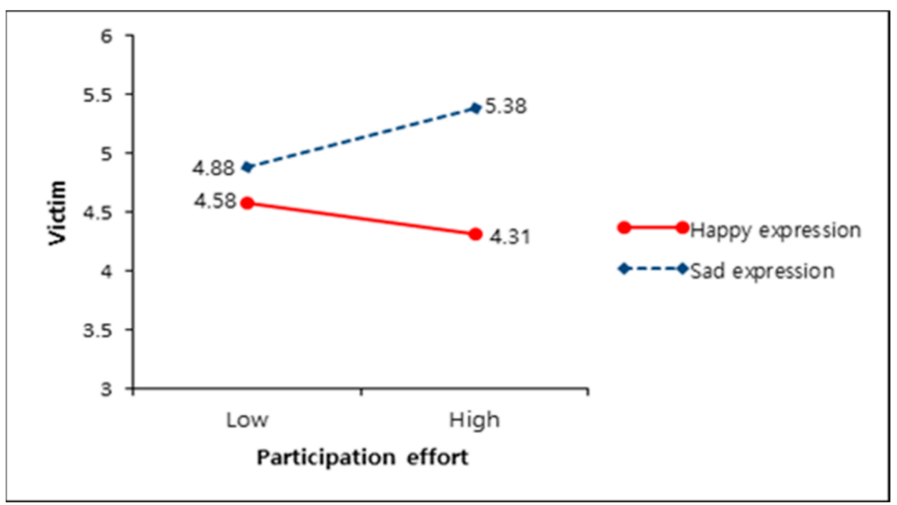

Figure 2. Interaction effects on victim.

\subsection{Marketing Agent Perception}

Following the results of ANCOVA on the perception of marketing agent, the main effects of the facial expression of anthropomorphic messenger $(\mathrm{F}=0.000, p>0.1)$ and participation effort $(\mathrm{F}=2.820, p>0.05)$ were not significant. However, more importantly, the two-way interaction effect of the two variables was significant $(\mathrm{F}=6.648, p<0.05)$. Contrast analysis showed that under the condition of happiness, participants perceived the messenger as a marketing agent when the participation effort was high $(\mathrm{M}=4.35)$ compared to when it was low $(\mathrm{M}=3.44 ; \mathrm{F}=9.086, p<0.01)$; however, there is no significant difference in marketing agent perception in the context of participation effort under the condition of sadness (high participation effort: 3.79 vs. low: 9.98, F $=0.418, p>0.1$ ) (see Figure 3). This supports Hypothesis 2.

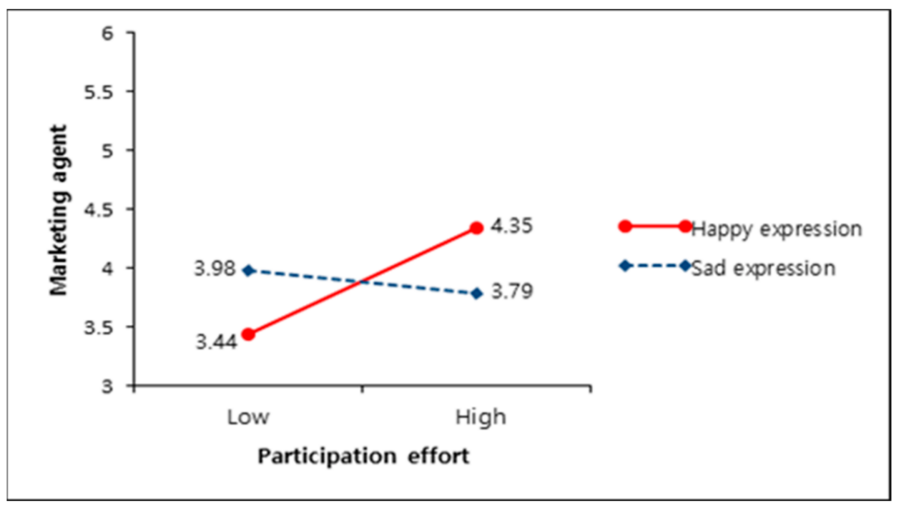

Figure 3. Interaction effects on marketing agent.

\subsection{Participation Intention}

As per the results of ANCOVA on participation intention, the main effects of the facial expression of anthropomorphic messenger $(\mathrm{F}=1.928, p>0.1)$ and participation effort $(\mathrm{F}=0.000, p>0.1)$ were not significant. However, the two-way interaction effect of the two variables was significant $(\mathrm{F}=12.358, p<0.01)$. Contrast analysis showed that under the condition of happiness, participants' intention to participate in CSR activities was more negative when the participation effort was high $(\mathrm{M}=4.59)$ compared to when it was low $(\mathrm{M}=5.12 ; \mathrm{F}=6.215, p<0.05)$; however, under the condition of sadness, their participation intention was more positive when the participation effort was high $(\mathrm{M}=5.56)$ compared to when it was low $(\mathrm{M}=5.00 ; \mathrm{F}=6.233, p<0.05)$ (see Figure 4). Hence, Hypothesis 3 is supported. Finally, the main effect of brand attitude, a covariate, was significant $(\mathrm{F}=42.500$, $p<0.001$ ). This means that the more positive the brand attitude is, the more positive is consumers' intention to participate in CSR activities. 


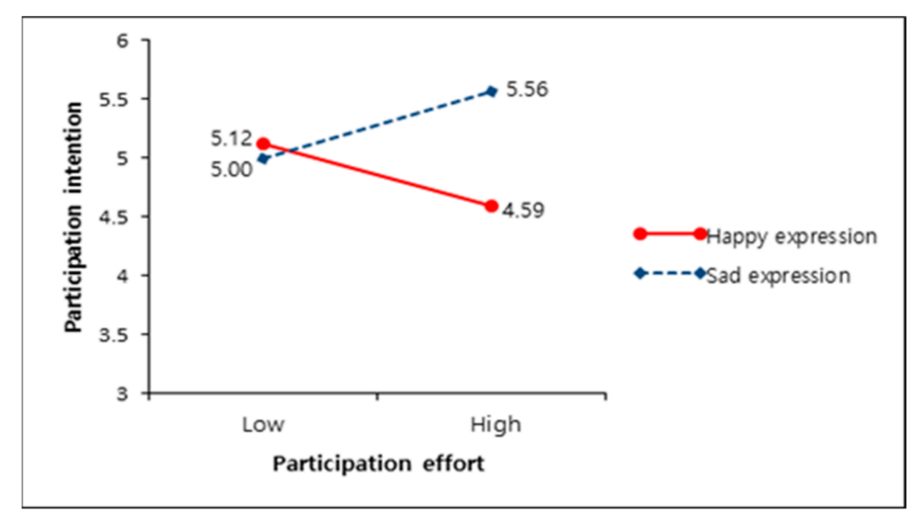

Figure 4. Interaction effects on participation intention.

\subsection{Mediation Analysis}

A mediated analysis was conducted to confirm the mechanisms (victim/marketing agent perception) in the effect of facial expression of the anthropomorphic messenger and the required participation effort on participation intention. Accordingly, model 8 of PROCESS macro was used [51], and bootstrapping analysis was performed with 10,000 resamples [52]. The results of the mediation analysis with participation effort as an independent variable, facial expression of the anthropomorphic messenger as a moderating variable, victim perception and marketing agent perception as mediating variables, participation intention as a dependent variable, and brand attitude as a covariate showed that the indirect effects of victim perception (indirect effect $=0.50,95 \%$ CI: $0.11 \sim 0.98$ ) and marketing agent perception (indirect effect $=0.16,95 \% \mathrm{CI}$ : 0.02 0.43) were significant. Therefore, Hypothesis 4 is supported.

\section{Discussion}

This study shows that anthropomorphic messengers in participatory CSR can be perceived by consumers as victims or marketing agents. This perception is determined by messengers' facial expression and participation effort. Specifically, consumers perceive an anthropomorphic messenger with a sad expression as a victim; as a result, the higher the participation effort is, the more positive their intention to participate in CSR is. On the contrary, consumers perceive a messenger exhibiting a happy expression as a marketing agent; as a result, participation effort negatively influences consumers' intention to participate. These results mean that all of our hypotheses $(\mathrm{H} 1-\mathrm{H} 4)$ were supported.

\section{Conclusions}

\subsection{Summary of Findings and Implications}

We revealed that the anthropomorphic messenger presented in participatory CSR can be perceived by consumers as two opposite roles (victim vs. marketing agent), and that the messenger's expression and participation efforts influence these consumer perceptions. This study provides the following academic implications. First, we examined the effect of anthropomorphism in the context of participatory CSR. In addition, we revealed that even though the messenger presented in the campaign was an anthropomorphic object, it would have the same effect on consumers' reaction if it were a person. Although previous studies have investigated the effects of CSR, currently, academic interest in participatory CSR is insufficient. Studies $[5,8]$ that investigated participatory CSR only examined the impact of participation effort. Therefore, the scope of research on participatory CSR is very limited. However, we focused on the role of anthropomorphism and participation effort required under participatory CSR. This study contributes to the diversity and expandability of related research through the application of two different research areas: participatory CSR and anthropomorphism. 
Second, we revealed that consumers' perceptions depend on the anthropomorphic messenger's facial expression. Ketron and Naletelich [16], who investigated the effectiveness of the anthropomorphism strategy presented in corporate eco-friendly campaigns, suggested the possibility that anthropomorphic messengers could be perceived by consumers either as a victim or marketing agent. We expanded their research by empirically verifying this role. In addition, our results show that consumers' perception of anthropomorphic messengers (victims and marketing agents) is determined not only by the messenger's facial expressions, but also through their interaction with participation effort. Hence, this study presented a clear mechanism related to the effect of anthropomorphic messenger's facial expression in the context of participatory CSR.

This study also provides the following practical implications. First, companies should consider how participation effort affects consumers' perceptions in the context of participatory CSR. Considering the results of this study, participation effort does not affect consumers' perceptions alone; it also interacts with the facial expressions of messengers. Hence, depending on the factors that are presented to consumers under participatory CSR, the influence of participation effort may be positive or negative. Therefore, when deciding the level of participation effort in the aspect of participatory CSR, companies should consider various factors that may affect consumers' perceptions.

Second, anthropomorphism is a strategy that companies can easily utilize to provide objects with the characteristics of individuals. The results of this study show that anthropomorphism is an effective strategy to convey emotions to consumers even in the context of participatory CSR. Additionally, the results show that the facial expression of anthropomorphic messengers influences consumers' perception of their role. In addition, according to the results of this study, participation effort further strengthens consumers' perception of the role of anthropomorphic messengers. Therefore, in the participatory CSR campaign, an anthropomorphism strategy using sad expressions is more suitable than that using a happy expression. It is recommended to present a high level of participation effort to consumers when implementing the anthropomorphism strategy using a sad expression. By raising consumers' awareness of a victim, companies will be able to positively change their intention to participate in CSR. However, if a high level of participation effort is presented in the context of using an anthropomorphic messenger exhibiting a happy expression, the effect of participatory CSR becomes negative. This is because it enhances consumers' knowledge of persuasion, making them doubt the purpose of the campaign.

\subsection{Limitations and Future Research}

The limitations of this study and suggestions for future research are as follows. First, all participation efforts in this study were presented as non-monetary costs. According to previous studies [16], the effort required by consumers to display eco-friendly behavior can not only be presented through non-monetary costs, but also through monetary costs. Therefore, future studies should necessarily set and check the efforts required under participatory CSR in more diverse ways.

Second, we conducted the study by recruiting 160 U.S. participants through Amazon MTurk. Prior studies suggested an appropriate sample size of 15-20 participants per independent variable [53]. Although the number of participants in this study is sufficient for analysis, it still has limitation to generalize research results. Additionally, even though we recruited demographically diverse participants using Amazon MTurk [54,55], this study has limitations in generalizing research results because all of the participants are U.S. citizens. In future research, it is recommended to increase the sample size and recruit more diverse participants in consideration of factors such as culture and nationality [54,55].

Third, participation efforts in this study were presented by manipulating the number of visits and number of coffee capsules that consumers should recycle. However, consumer participation efforts may differ depending on the type of campaign that is being executed. For example, Ahn and Lee [5] presented participation effort as the number of mobile applications accessed by consumers; Howie et al. [8] manipulated it by the number of 
website access time and questionnaire questions. Therefore, it is necessary for future studies to conduct analyses by manipulating the participation effort to achieve generalized results.

Forth, we anthropomorphized the Earth and trees as the targets of benefits in the campaigns of this study. Future studies should anthropomorphize various objects, and consider the fit between an anthropomorphic messenger and the context in which its anthropomorphism is being presented. For example, the fit of an anthropomorphic messenger and its context may be low when a crying bee is presented in resource-rich situations, such as a variety of flowers in full bloom, or a polar bear laughing on melting ice. In such cases, consumers can have a negative attitude regardless of the anthropomorphic messenger's facial expression.

Finally, future studies should focus on conducting experiments with more diverse expressions of anthropomorphic messengers. It may be better to consider the influence of facial expressions through cultural characteristics. According to Bennett [56], individuals sharing Eastern cultures perceive facial expressions by focusing on the eyes of the subject, while individuals in Western cultures perceive facial expressions by focusing on the mouth of the subject. Therefore, in future studies, it will be interesting to examine how the shape of anthropomorphic messengers' eyes and mouths, or their presence or absence may affect consumers' responses in different cultures.

Author Contributions: Conceptualization, Y.A. and J.L.; methodology, J.L.; analysis, Y.A.; writingoriginal draft preparation, Y.A.; writing - review and editing, J.L. Both authors have read and agreed to the published version of the manuscript.

Funding: This research received no external funding.

Institutional Review Board Statement: Not applicable.

Informed Consent Statement: Informed consent was obtained from all subjects involved in the study.

Data Availability Statement: The authors confirm that the datasets analyzed during the study are available from the first author or the corresponding author upon reasonable request.

Conflicts of Interest: The authors declare no conflict of interest.

\section{Appendix A. Examples of Stimuli}

Adidas is now conducting a new corporate social responsibility (CSR) campaign to encourage consumers to participate. Specifically, Adidas will develop and launch ecofriendly sneakers made from used plastic bottles. In this campaign, consumers are required to recycle plastic bottles using reverse vending machine.

If they use this machine only one time (20 times), Adidas will produce a pair of eco-friendly sneakers. In other words, a single consumer participation recycling event (20 times) can help Adidas launch eco-friendly sneakers.

The CSR ads of Adidas are as follows:

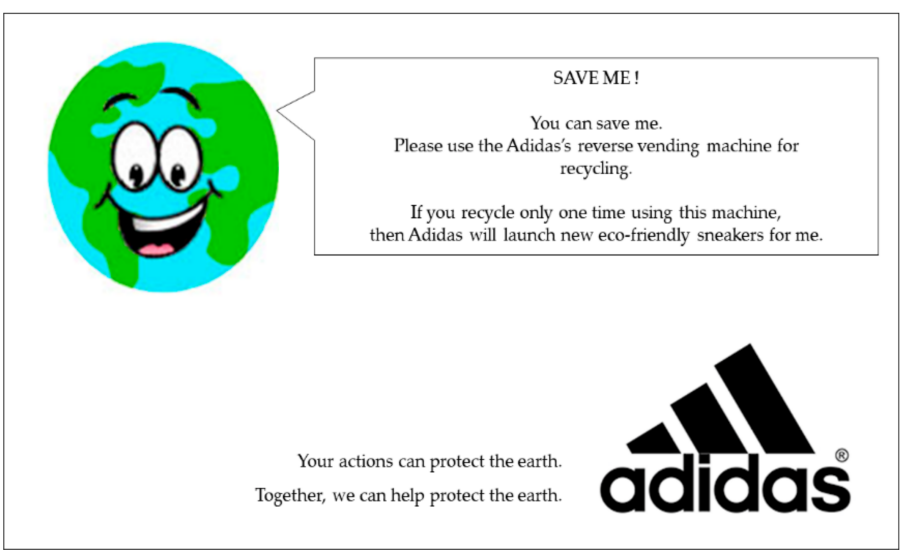

Figure A1. Happy expression condition. 


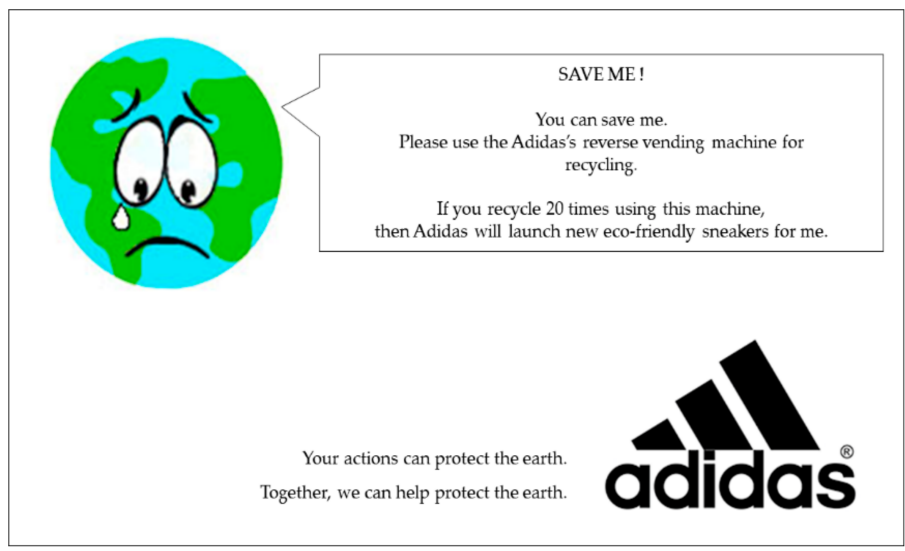

Figure A2. Sad expression condition.

\section{References}

1. Mitchel, M. Top Corporate Cocial Responsibility Trends in 2020. Available online: https://www.smartrecruiters.com/blog/topcorporate-social-responsibility-trends-in-2020 / (accessed on 21 May 2020).

2. Cho, S.J.; Chung, C.Y.; Young, J. Study on the relationship between CSR and financial performance. Sustainability 2019, 11, 343. [CrossRef]

3. Khojastehpour, M.; Shams, S.R. Addressing the complexity of stakeholder management in international ecological setting: A CSR approach. J. Bus. Res. 2020, 119, 302-309. [CrossRef]

4. Entrepreneur. Despite the COVID-19 Crisis, Dubai's Commitment to Sustainability and Corporate Social Responsibility Remains Strong in 2020. Available online: https:/ / www.entrepreneur.com/article/362162 (accessed on 23 December 2020).

5. Ahn, Y.; Lee, J. The effect of participation effort on CSR participation intention: The moderating role of construal level on consumer perception of warm glow and perceived costs. Sustainability 2020, 12, 83. [CrossRef]

6. Company, T.C.-C. Coke Piloting Kiosks That Reward Recycling with Charitable Donations. Available online: https://www.cocacolacompany.com/news/coke-piloting-kiosks-that-reward-recycling (accessed on 27 July 2018).

7. Government, S.M. Art Health Donation Stairs for Those Who Walk Up Stairs in Subways to Support Artists with Disabilities. Available online: http:/ / english.seoul.go.kr/art-health-donation-stairs-for-those-who-walk-up-stairs / (accessed on 16 January 2020).

8. Howie, K.M.; Yang, L.; Vitell, S.J.; Bush, V.; Vorhies, D. Consumer participation in cause-related marketing: An examination of effort demands and defensive denial. J. Bus. Ethics 2018, 147, 679-692. [CrossRef]

9. Yang, L.W.; Aggarwal, P.; McGill, A.L. The 3 C's of anthropomorphism: Connection, comprehension, and competition. Consum. Psychol. Rev. 2020, 3, 3-19. [CrossRef]

10. Wang, X.; Ming, M.; Zhang, Y. Are "people" or "animals" more attractive? Anthropomorphic images in green-product advertising. J. Clean. Prod. 2020, 276, 122719. [CrossRef]

11. Wilson, H.; Daugherty, P.; Bianzino, N. When AI Becomes the New Face of Your Brand. Available online: https://hbr.org/2017/0 6/when-ai-becomes-the-new-face-of-your-brand (accessed on 27 June 2017).

12. Witsil, F. Smokey Bear Gets a New Voice for His 75th Birthday. Available online: https:/ / www.seattletimes.com/nation-world/ smokey-bear-gets-a-new-voice-for-his-75th-birthday/ (accessed on 21 April 2019).

13. McCallum, W. 'Turtle Journey' Shows Us Why We Urgently Need to Protect the Oceans. Available online: https://www. greenpeace.org/international/story/28229/turtle-journey-urgent-protect-the-oceans/ (accessed on 17 January 2020).

14. Bhati, A.; Eikenberry, A.M. Faces of the needy: The portrayal of destitute children in the fundraising campaigns of NGOs in India. Int. J. Nonprofit Volunt. Sect. Mark. 2016, 21, 31-42. [CrossRef]

15. Gupta, R.; Srinivasan, N. Only irrelevant sad but not happy faces are inhibited under high perceptual load. Cogn. Emot. 2015, 29, 747-754. [CrossRef]

16. Ketron, S.; Naletelich, K. Victim or beggar? Anthropomorphic messengers and the savior effect in consumer sustainability behavior. J. Bus. Res. 2019, 96, 73-84. [CrossRef]

17. Boulouta, I.; Pitelis, C.N. Who needs CSR? The impact of corporate social responsibility on national competitiveness. J. Bus. Ethics 2014, 119, 349-364. [CrossRef]

18. Pérez, A.; Del Bosque, I.R. Measuring CSR image: Three studies to develop and to validate a reliable measurement tool. J. Bus. Ethics 2013, 118, 265-286. [CrossRef]

19. Murcia, M.J. Progressive and rational CSR as catalysts of new product introductions. J. Bus. Ethics 2020, 1-15. [CrossRef]

20. Beise-Zee, R. Corporate social responsibility or cause-related marketing? The role of cause specificity of CSR. J. Consum. Mark. 2011, 28, 27-39. [CrossRef] 
21. Chu, S.C.; Chen, H.T. Impact of consumers' corporate social responsibility-related activities in social media on brand attitude, electronic word-of-mouth intention, and purchase intention: A study of Chinese consumer behavior. J. Consum. Behav. 2019, 18, 453-462. [CrossRef]

22. Yoon, Y.; Gürhan-Canli, Z.; Schwarz, N. The effect of corporate social responsibility (CSR) activities on companies with bad reputations. J. Consum. Psychol. 2006, 16, 377-390. [CrossRef]

23. Sen, S.; Bhattacharya, C.B. Does doing good always lead to doing better? Consumer reactions to corporate social responsibility. J. Mark. Res. 2001, 38, 225-243. [CrossRef]

24. Lee, S.S.; Kim, Y.; Roh, T. Modified pyramid of CSR for corporate image and customer loyalty: Focusing on the moderating role of the CSR experience. Sustainability 2019, 11, 4745. [CrossRef]

25. Luo, X.; Bhattacharya, C.B. Corporate social responsibility, customer satisfaction, and market value. J. Mark. 2006, 70, 1-18. [CrossRef]

26. Chang, C.T. To donate or not to donate? Product characteristics and framing effects of cause-related marketing on consumer purchase behavior. Psychol. Mark. 2008, 25, 1089-1110. [CrossRef]

27. Tao, W.; Ji, Y.G. Firm-determined or consumer-determined corporate social responsibility (CSR)? Examining the effects of choice-of-cause in cause-related marketing. Int. J. Bus. Commun. 2020, 1-24. [CrossRef]

28. Abbas, M.; Gao, Y.; Shah, S.S.H. CSR and customer outcomes: The mediating role of customer engagement. Sustainability 2018, 10, 4243. [CrossRef]

29. Ruiz de Maya, S.; Lardín-Zambudio, R.; López-López, I. I will do it if I enjoy it! the moderating effect of seeking sensory pleasure when exposed to participatory CSR campaigns. Front. Psychol. 2016, 6, 1940. [CrossRef] [PubMed]

30. Folse, J.A.G.; Niedrich, R.W.; Grau, S.L. Cause-relating marketing: The effects of purchase quantity and firm donation amount on consumer inferences and participation intentions. J. Retail. 2010, 86, 295-309. [CrossRef]

31. Habel, J.; Schons, L.M.; Alavi, S.; Wieseke, J. Warm glow or extra charge? The ambivalent effect of corporate social responsibility activities on customers' perceived price fairness. J. Mark. 2016, 80, 84-105. [CrossRef]

32. Tsai, C.I.; McGill, A.L. No pain, no gain? How fluency and construal level affect consumer confidence. J. Consum. Res. 2011, 37, 807-821. [CrossRef]

33. DiGirolamo, M.A.; Russell, J.A. The emotion seen in a face can be a methodological artifact: The process of elimination hypothesis. Emotion 2017, 17, 538-546. [CrossRef] [PubMed]

34. Septianto, F.; Paramita, W. Sad but smiling? How the combination of happy victim images and sad message appeals increase prosocial behavior. Mark. Lett. 2020, 32, 91-110. [CrossRef]

35. Lohmann, K.; Pyka, S.S.; Zanger, C. The effects of smileys on receivers' emotions. J. Consum. Mark. 2017, 34, 489-495. [CrossRef]

36. Small, D.A.; Verrochi, N.M. The face of need: Facial emotion expression on charity advertisements. J. Mark. Res. 2009, 46, 777-787. [CrossRef]

37. Zemack-Rugar, Y.; Klucarova-Travani, S. Should donation ads include happy victim images? The moderating role of regulatory focus. Mark. Lett. 2018, 29, 421-434. [CrossRef]

38. Liang, J.; Chen, Z.; Lei, J. Inspire me to donate: The use of strength emotion in donation appeals. J. Consum. Psychol. 2016, 26, 283-288. [CrossRef]

39. McLellan, T.; Johnston, L.; Dalrymple-Alford, J.; Porter, R. Sensitivity to genuine versus posed emotion specified in facial displays. Cogn. Emot. 2010, 24, 1277-1292. [CrossRef]

40. Kim, S.; McGill, A.L. Gaming with Mr. Slot or gaming the slot machine? Power, anthropomorphism, and risk perception. J. Consum. Res. 2011, 38, 94-107. [CrossRef]

41. Lee, S.A.; Oh, H. Anthropomorphism and its implications for advertising hotel brands. J. Bus. Res. 2019, 129, 455-464. [CrossRef]

42. Wang, W. Smartphones as social actors? Social dispositional factors in assessing anthropomorphism. Comput. Hum. Behav. 2017, 68, 334-344. [CrossRef]

43. Maeng, A.; Aggarwal, P. Facing dominance: Anthropomorphism and the effect of product face ratio on consumer preference. J. Consum. Res. 2018, 44, 1104-1122. [CrossRef]

44. Tong, Z.; Li, T.; Feng, J.; Zhang, Q. Using images of eyes to enhance green brand purchase intentions through green brand anthropomorphism strategies: The moderator role of facial expression. Front. Psychol. 2020, 11, 568595. [CrossRef]

45. Kivetz, R.; Simonson, I. Earning the right to indulge: Effort as a determinant of customer preferences toward frequency program rewards. J. Mark. Res. 2002, 39, 155-170. [CrossRef]

46. Xia, L.; Kukar-Kinney, M.; Monroe, K.B. Effects of consumers' efforts on price and promotion fairness perceptions. J. Retail. 2010, 86, 1-10. [CrossRef]

47. Folse, J.A.G.; Burton, S.; Netemeyer, R.G. Defending brands: Effects of alignment of spokescharacter personality traits and corporate transgressions on brand trust and attitudes. J. Advert. 2013, 42, 331-342. [CrossRef]

48. DeCarlo, T.E.; Laczniak, R.N.; Leigh, T.W. Selling financial services: The effect of consumer product knowledge and salesperson commission on consumer suspicion and intentions. J. Acad. Mark. Sci. 2013, 41, 418-435. [CrossRef]

49. Feiler, D.C.; Tost, L.P.; Grant, A.M. Mixed reasons, missed givings: The costs of blending egoistic and altruistic reasons in donation requests. J. Exp. Soc. Psychol. 2012, 48, 1322-1328. [CrossRef]

50. Grau, S.L.; Folse, J.A.G. Cause-related marketing (CRM): The influence of donation proximity and message-framing cues on the less-involved consumer. J. Advert. 2007, 36, 19-33. [CrossRef] 
51. Preacher, K.J.; Hayes, A.F. Asymptotic and resampling strategies for assessing and comparing indirect effects in multiple mediator models. Behav. Res. Methods 2008, 40, 879-891. [CrossRef]

52. Zhao, X.; Lynch, J.G., Jr.; Chen, Q. Reconsidering Baron and Kenny: Myths and truths about mediation analysis. J. Consum. Res. 2010, 37, 197-206. [CrossRef]

53. Hair, J.F.; Black, W.C.; Babin, B.J.; Anderson, R.E.; Tatham, R.L. Pearson new international edition. In Multivariate Data Analysis, 7th ed.; Pearson Education Limited Harlow, Essex: London, UK, 2014.

54. Buhrmester, M.; Kwang, T.; Gosling, S.D. Amazon's mechanical turk: A new source of inexpensive, yet high-quality, data? Perspect. Psychol. Sci. 2011, 6, 3-5. [CrossRef]

55. Paolacci, G.; Chandler, J.; Ipeirotis, P.G. Running experiments on amazon mechanical turk. Judgm. Decis. Mak. 2010, 5, 411-419.

56. Bennett, C.C. The effects of culture and context on perceptions of robotic facial expressions. Interact. Stud. 2015, 16, 272-302. [CrossRef] 